\title{
A EDUCAÇÃO EM DIREITOS HUMANOS E OS MARCOS LEGAIS NORTEADORES
}

\author{
HUMAN RIGHTS EDUCATION AND LEGAL GUIDING MARKS
}

LA EDUCACIÓN EN DERECHOS HUMANOS Y LAS DIRECTRICES LEGALES

\author{
Jacqueline Lopes Freire \\ Mestra em Educação pela Universidade de Uberaba (UNIUBE) e doutoranda em Educação pela \\ Universidade Federal de Uberlândia (UFU). Uberaba/MG, Brasil. \\ ORCID https://orcid.org/0000-0002-7908-0191 \\ jacquelinelfreire@gmail.com \\ José Carlos Souza Araújo \\ Doutor em Educação pela Universidade de Campinas (UNICAMP), professor do Programa de Pós- \\ graduação em Educação da UFU e da UNIUBE. Uberlândia/MG, Brasil. \\ ORCID https://orcid.org/0000-0002-7972-8875 \\ jcaraujo.ufu@gmail.com
}

\begin{abstract}
Resumo
Propomos nesse texto recuperar o sentido e a historicidade da educação em direitos humanos (EDH) no Brasil. Buscamos apresentar a objetivação dos princípios garantidos em documentos internacionais nos planos nacionais para EDH. Para tanto, partimos da apresentação dos principais marcos legais vigentes e norteadores do tema sobre o direito à educação e a EDH, nos instrumentos internacionais e no ordenamento nacional. Esse movimento nos permitiu compreender que, na seara normativa, a educação e a formação de uma cultura em direitos humanos são tomadas como instrumentos capazes de objetivar os direitos humanos e a garantia da dignidade humana a todos. Nesse sentido, o Estado brasileiro assumiu ao longo dos anos de 1990 a 2000 tais fundamentos na elaboração de seus planos de EDH, com o objetivo de construir uma cultura formativa em direitos humanos. A presente pesquisa bibliográfica, documental e de cunho qualitativa, respaldada em BONAVIDES (1998), CANDAU (2007), ZENAIDE (2007), entre outros, concluiu que a despeito dos programas de ação, planos e do complexo legislativo acerca da educação como direito humano, o debate não merece ser considerado apenas como seara normativa. A efetivação da EDH depende de políticas públicas capazes gerar práticas sociais que reflitam na maneira de pensar, sentir e agir da coletividade.
\end{abstract}

Palavras chaves: Educação; Educação em Direitos Humanos; Contextualização normativa internacional e nacional.

\begin{abstract}
We propose in this text to recover the meaning and the historicity of human rights education in Brazil. For this purpose, we started by the main current legal guiding marks about education rights and HRE, in international and national codes. This movement allowed us to comprehend that, in normative area, education and the setting up of human rights and the guarantee of human dignity to everyone are seen as effective tools. In this regard, Brazilian State assumed, from 1990 to 2000, this basis in the elaboration of HRE plans, in order to build a formative culture in human rights. The bibliographic research, documental and qualitative, supported by BONAVIDES (1998), CANDAU (2007), ZENAIDE (2007), among others, concluded that, in spite of several action programs, plans and the vast amount of laws regarding education as a human right, the debate is far beyond ruling area. The HRE realization depends on public politics capable of creating social activities which reflect on the way people think, feel and act.
\end{abstract}

Key words: Education; Human Rights Education; national and international contextualization. 


\section{Resumen}

Proponemos en este texto recuperar el significado y la historicidad de la educación en derechos humanos (EDH) en Brasil. Buscamos presentar la objetivación de los principios garantizados en documentos internacionales en los planes nacionales de EDH. Para ello, partimos de la presentación de los principales marcos legales vigentes y orientando la temática sobre el derecho a la educación y la EDH, en los instrumentos internacionales y en el orden nacional. Este movimiento permitió comprender que, en el ámbito normativo, la educación y la formación de una cultura en derechos humanos se toman como instrumentos capaces de objetivar los derechos humanos y garantizar la dignidad humana a todos. En este sentido, el Estado brasileño asumió durante las décadas de 1990 a 2000 tales fundamentos en la elaboración de sus planes EDH, con el objetivo de construir una cultura formativa en derechos humanos. La presente investigación bibliográfica, documental y cualitativa, apoyada por Bonavids (1998), CANDAU (2007), ZENAIDE (2007), entre otros, concluyó que a pesar de los programas de acción, planes y el complejo legislativo sobre la educación como derecho, el debate no merecen ser considerados meramente como un área normativa. La efectividad de la EDH depende de políticas públicas capaces de generar prácticas sociales que reflejen la forma de pensar, sentir y actuar en la comunidad.

Palabras clave: Educación; Educación en derechos humanos; Contexto regulatorio internacional y nacional.

\section{INTRODUÇÃO}

Falar em direitos humanos nos incita refletir sobre a defesa da dignidade humana, um dos fundamentos da República brasileira, constituído de natureza normativa, imperativa e constitucional. Um princípio supremo da pessoa humana que orienta os demais direitos fundamentais. A dignidade da pessoa humana é um princípio que se destina tanto à proteção da vida individual, quanto coletiva. Sua aplicabilidade volta-se à preservação da vida do indivíduo como um fim em si mesmo e como autonomia de sua vontade, conforme defende Immanuel Kant (apud ABBAGNANO, 2007). Segundo a concepção aludida, face à racionalidade, as ações humanas voltadas para o próprio sujeito ou para outrem (para a esfera individual ou coletiva), tem como fim a vida humana, baseando o resultado de suas condutas pela dignidade e pela autonomia da vontade, como princípio supremo da moralidade.

A concepção de dignidade humana como fim da condição humana, e não como meio, se relaciona ao princípio da igualdade para se materializar. No campo dos princípios é comum o entusiasmo com seus enunciados, contudo, a sua aplicabilidade deve ser vista com cautela pois é sempre circunstanciada pela situação histórica. Nessa linha, deve-se analisar o princípio da igualdade com ressalvas, pois esta pode assumir uma dimensão insuficiente a depender da aplicabilidade. O sentido puro e literal da igualdade não observa o indivíduo dentro de suas peculiaridades, massifica e homogeneíza as necessidades de todos em um só campo, de forma a discriminar e diferenciar os sujeitos. Portanto, dentro desta limitação interpretativa, “a igualdade não consiste senão 
em quinhoar desigualmente aos desiguais, na medida em que se desigualam. Nesta desigualdade social, proporcionada à desigualdade natural, é que se acha a verdadeira lei da igualdade" (BARBOSA, 1999, p. 26).

Desse modo, a igualdade deve assumir, na composição da dignidade da pessoa humana, uma natureza real e material, corrigindo as acentuadas desigualdades existentes na sociedade, dando oportunidade e assegurando condições de exercício de direitos aos grupos historicamente marginalizados e vitimizados na sociedade. É exatamente nessa perspectiva coletiva, pela promoção ao bem-estar social, que o direito à educação, como direito fundamental social, é considerado um direito humano, e encampado por diversas legislações e tratados em âmbito mundial, como forma de promover igualdade de condições e de acesso a bens imateriais e materiais ao homem.

A educação em direitos humanos segue essa perspectiva teórica e política, enquanto necessidade para a vida em sociedade. Historicamente os direitos humanos se tornaram uma demanda social em períodos em que a sociabilidade encontrava-se em momentos de crise político-econômica, e as individualidades foram confrontadas pela exploração, miséria e desigualdade social. Candau (2000, p. 12) afirma que "a superação dos sistema políticos autoritários na grande maioria dos países do continente e a construção de democracias autênticas supõe processos em que a conquista dos direitos humanos seja cada vez mais real e efetiva". Nesses momentos de instabilidade, portanto, foram elaboradas declarações e legislações, bem como emergiram instituições jurídicas de defesa da dignidade humana contra a violência, a opressão e o aviltamento. Observa-se que os direitos humanos nunca foram plenamente respeitados e implementados nas sociedades da maneira como proclamados nos tratados e pactos internacionais, tal como na Declaração Universal dos Direitos Humanos de 1948.

A consciência social em torno dos direitos humanos, no entanto, vem se tornando cada vez mais forte na história. Contudo, esses direitos tão proclamados são sistematicamente violados. Isso faz com que cresça a tensão entre a promoção e a defesa dos direitos humanos, face à sua constante violação, tornando-se, para nós, um grande desafio efetivá-los. Nesse sentido, deve-se encarar que a luta pelos direitos humanos se dá no cotidiano, e em todas as relações sociais. O debate não merece ser considerado apenas como convicção teórica, mas deve ser concretizado na prática social e capaz de marcar a 
maneira de pensar, sentir e agir da coletividade, em especial, com a efetiva adoção de políticas públicas.

Nesse sentido, concordamos com Candau (2000) que a luta pelos direitos humanos, por estabelecer nas consciências dos indivíduos o compromisso pela promoção dos direitos entre os indivíduos e grupos sociais, passa obrigatoriamente pela educação, em suas diferentes formas de manifestação, inclusive na escolar. Segundo a autora, é a escola que deveria exercer a função de humanizar os indivíduos por meio da aquisição do conhecimento e de valores para a conquista e exercício da cidadania plena. Apesar disso, historicamente, as instituições escolares têm mantido o status quo social, refletindo as desigualdades sociais e reforçando as diferenças entre os grupos étnicos e sociais.

Na sociedade brasileira, marcada culturalmente por opressões de diferentes ordens (classe, raça, gênero, dentre outros), explorações e injustiças sociais, a cidadania não pode ser entendida unicamente em sua dimensão jurídico-formal. Isso significa dizer, que a cidadania não pode ser reduzida à tomada de consciência pelo indivíduo de seus deveres e direitos cívicos. Exercer a cidadania requer o reconhecimento e a denúncia da violação dos direitos sociais pela sociedade. Portanto, educar para a cidadania exige o fortalecimento de uma cultura democrática, tão rara na história republicana brasileira. Nessa proposta, o ambiente escolar surge como um espaço propício para promover a socialização e a elaboração do conhecimento e dos valores morais e sociais necessários à formação em direitos humanos e à conquista e ao exercício da cidadania.

Os principais documentos orientadores e reguladores do direito à educação e da educação em direitos humanos (EDH) destacam a importância em direcionar o indivíduo ao pleno desenvolvimento humano e as suas potencialidades, valorizando o respeito aos grupos socialmente excluídos. Nessa concepção, a EDH propõe-se à efetivação da cidadania plena, por meio da construção de conhecimentos, do desenvolvimento de valores, atitudes, práticas de liberdade e emancipatórias, além da defesa da justiça social, em prol da transformação e da mudança.

O presente texto dedica-se a recuperar o sentido e a historicidade à educação em direitos humanos no Brasil. Buscamos com essa finalidade apresentar a objetivação dos princípios garantidos em documentos internacionais em planos nacionais para EDH. Partimos, portanto, da apresentação dos principais marcos legais vigentes e norteadores do debate sobre o direito à educação e a EDH, tanto nos instrumentos internacionais de 
Direitos Humanos, quanto no ordenamento legal brasileiro. Em um primeiro momento, indicamos os principais marcos e referenciais internacionais, para posteriormente tratar das políticas educacionais brasileiras para educação em direitos humanos.

\section{Dos princípios - marcos legais internacionais referenciais para a educação em direitos humanos no Brasil}

Os direitos civis e políticos tornaram-se demanda social em contextos de revoltas (ou revoluções) sociais que, em geral, materializaram práticas coletivas que feriram a dignidade humana ou colocaram a vida dos indivíduos em risco. Assim foi com a Revolução Gloriosa, na Inglaterra, de 1688 a 1689, em que resultou a Bill of Rights, a guerra de independência dos Estados Unidos da América, de 1776 a 1783, e sua Constituição Federal, a Revolução Francesa, 1789 a 1799, e a conhecida Declaração dos Direitos do Homem e do Cidadão e, mais recentemente, a II Guerra Mundial, 1939 a 1945, que culminou na Declaração Universal dos Direitos Humanos, de 1948.

Neste contexto, a base histórica sobre a cultura moderna dos direitoso leva em consideração, primordialmente, as revoluções liberais ocorridas na Inglaterra e na França no final do século XVII e XVIII, respectivamente:

\footnotetext{
Nessa época, ainda não são Direitos Humanos, mas direitos civis e políticos, codificados na inglesa Bill of Rights e na francesa Declaração dos Direitos do Homem e do Cidadão, que buscavam assegurar, juridicamente, direitos para os membros de seus respectivos Estados Nacionais, consignando-os como cidadãos. (SILVEIRA, 2007, p. 275).
}

Atualmente, a Declaração Universal dos Direitos Humanos, de 1948, têm norteado as orientações que definem políticas públicas sobre direitos humanos para os Estadosnação, em vista do reconhecimento das liberdades fundamentais e da dignidade inerente a todos os seres humanos, como forma de prevenção às violências, institucionais e sociais, contra a humanidade. Em linhas iniciais, o tema educação, nos pactos internacionais, é estabelecido como um direito humano que deve fortalecer a construção dos sujeitos na condição de dignidade que a humanidade precisa, em outras palavras, como sujeitos de direitos. Ganha força e relevância a cada documento internacional elaborado como instrumento capaz e fundamental na formação de uma cultura em direitos humanos. 
Decorrente dessa orientação, no cenário mundial, passaram a ser elaboradas documentos que versam sobre os direitos humanos e possuem a educação como um dos seus pressupostos. Esses documentos internacionais influenciaram a elaboração de políticas públicas brasileiras na promoção da cultura em Direitos Humanos. Abaixo, no Quadro I, elencamos os principais tratados e pactos internacionais que incidiram no ordenamento jurídico brasileiro. À medida que apresentamos sumariamente os documentos, indicamos as suas incidências na legislação nacional e demonstramos o progressivo avanço nas conquistas e garantias por uma educação em direitos humanos.

Quadro 1 - Demarcações internacionais para uma Educação em Direitos Humanos

\begin{tabular}{|c|c|c|}
\hline Ano & Documento & Incorporação ao direito brasileiro \\
\hline 1948 & $\begin{array}{l}\text { Declaração Universal dos Direitos } \\
\text { Humanos (DUDH) }\end{array}$ & $\begin{array}{l}\text { Automaticamente incorporada ao } \\
\text { direito pátrio no ato de sua } \\
\text { proclamação, em } 10 \text { de Dezembro de } \\
\text { 1948; }\end{array}$ \\
\hline 1966 & $\begin{array}{l}\text { Pacto Internacional dos Direitos } \\
\text { Econômicos, Sociais e Culturais } \\
\text { (PIDESC) }\end{array}$ & $\begin{array}{l}\text { Decreto Federal } n^{\circ} 591 \text {, de } 06 \text { de julho } \\
\text { de 1992; }\end{array}$ \\
\hline 1988 & Protocolo de San Salvador (1988) & $\begin{array}{l}\text { Decreto Federal } n^{\circ} 3.321 \text {, de } 31 \text { de } \\
\text { dezembro de 1999; }\end{array}$ \\
\hline 1993 & $\begin{array}{l}\text { Il Conferência Mundial de Direitos } \\
\text { Humanos }\end{array}$ & $\begin{array}{l}\text { Programa de Ação da Conferência } \\
\text { Mundial de Direitos Humanos, em } \\
\text { 1993; }\end{array}$ \\
\hline 1994 & $\begin{array}{l}\text { Década das Nações Unidas para a } \\
\text { Educação em Direitos Humanos } \\
\text { (período de } 1^{\circ} \text { de janeiro de } 1995 \text { a } \\
31 \text { de dezembro de 2004) }\end{array}$ & $\begin{array}{l}\text { Resolução } n^{\circ} 49 / 184 \text { da ONU, aprovada } \\
\text { pela Assembleia Geral em } 23 \text { de } \\
\text { Dezembro de } 1994 \text {. }\end{array}$ \\
\hline
\end{tabular}

Fonte: elaborado pelos autores.

A Declaração Universal dos Direitos Humanos (DUDH) foi promulgada pelas Organização das Nações Unidas (ONU), em 10 de dezembro de 1948. Considerada como instrumento pioneiro de propostas para a construção de uma cultura universal de promoção aos direitos humanos, em âmbito internacional, exigiu dos países signatários processos de revisão e inovação dos ordenamentos jurídicos internos para possibilitar o reconhecimento e a defesa dos direitos fundamentais do homem. 
Mondaini (2013) esclarece que os ciclos para a consolidação da universalização dos direitos humanos decorreram, em primeiro plano, com a criação da ONU em 1945, e após, com a promulgação da DUDH em 1948, como uma resposta da sociedade contra os atos de violações de direitos e as atrocidades experienciados na Segunda Guerra Mundial. A Declaração tem como fundamento, dentre outros, a formação de consciência da humanidade, visando a liberdade de manifestação, de pensamento e de crenças, contra atos de barbárie, e pela proteção aos direitos, para que o "homem não seja compelido, em supremo recurso, à revolta contra a tirania e a opressão". (DECLARAÇÃO, 1948, n/p.). A referida proclamação vale-se do ensino, da educação e da instrução, como processo formativo do indivíduo e como mecanismo capaz de promover-lhes a tão almejada liberdade e o gozo dos direitos. Vejamos a sua redação.

\begin{abstract}
A Assembleia Geral das Nações Unidas proclama a presente "Declaração Universal dos Direitos do Homem" como o ideal comum a ser atingido por todos os povos e todas as nações, com o objetivo de que cada indivíduo e cada órgão da sociedade, tendo sempre em mente esta Declaração, se esforce, através do ensino e da educação, por promover o respeito a esses direitos e liberdades, e, pela adoção de medidas progressivas de caráter nacional e internacional, por assegurar o seu reconhecimento e a sua observância universais e efetivos, tanto entre os povos dos próprios Estados Membros, quanto entre os povos dos territórios sob sua jurisdição. (DECLARAÇÃO, 1948, n/p. grifos nossos).
\end{abstract}

Esse documento, enquanto marco ético, jurídico e político, resulta em obrigações para os Estados-Membros de construção de uma cultura em Direitos Humanos para as atuais e futuras gerações. Para tanto, considera o ensino e a educação como ferramentas capazes de garantir o respeito aos Direitos do Homem, à liberdade, no sentido do pleno desenvolvimento da personalidade humana, a tolerância, a paz e a solidificação da cidadania e da ordem democrática. O que veremos a seguir são documentos internacionais que reafirmam o direito à educação e a sua importância à promoção de uma cultura em Direitos Humanos. É sobre esse ponto que daremos destaque em todos os documentos que apresentarmos.

A publicação da Declaração Universal dos Direitos Humanos foi um marco, pois a partir dela outras foram redigidas e criadas para condicionar a implantação nos espaços nacionais da cultura em Direitos Humanos. A exemplo, citamos o Pacto Internacional dos Direitos Econômicos, Sociais e Culturais (PIDESC), de 1966. O Pacto tratou e ratificou os 
direitos sociais relativos ao trabalho e à justa remuneração, a formar e a associar-se em sindicatos, à educação, direito das crianças de não serem exploradas e o direito à participação na vida cultural da comunidade. A novidade apresentada pelo pacto foi tornar juridicamente vinculante os dispositivos da DUDH e passou a responsabilizar os Estadosparte pela violação dos direitos enumerados. No artigo $2^{\circ}$, item I do Pacto lê-se:

Cada Estado-parte no presente Pacto, compromete-se a adotar medidas, tanto por esforços próprios, como pela assistência e cooperação internacionais, principalmente nos planos econômicos e técnicos, até o máximo de seus recursos disponíveis, que visem a assegurar, progressivamente, por todos os meios apropriados, o pleno exercício dos direitos reconhecidos no presente Pacto, incluindo, em particular, a adoção de medidas legislativas. (PACTO, 1966, n/p.).

Quando da publicação do Pacto, o Brasil vivenciava uma ditadura civil-militar, marcada por um governo autoritário que cassou direitos civis e políticos de parte da população e infringiu os direitos humanos censurando, reprimindo, torturando e assassinando vozes destoantes daqueles que discordavam de suas políticas. Somente com o fim da ditadura, após vinte e seis anos, contados de sua edição, o referido pacto Internacional foi referendado no Brasil pelo Congresso Nacional, por intermédio do Decreto Federal $n^{\circ} 591$ de 1992, em vigor desde 06 de julho do mesmo ano. Para o mencionado ato, a educação, como direito de todos, visará o pleno desenvolvimento da personalidade humana, da dignidade, o fortalecimento e respeito aos direitos humanos e, as liberdades fundamentais. Os signatários anuíram que a educação capacitará

todas as pessoas a participar efetivamente de uma sociedade livre, favorecer a compreensão, a tolerância e a amizade entre todas as nações e entre todos os grupos raciais, étnicos ou religiosos e promover as atividades das Nações Unidas em prol da manutenção da paz. (BRASIL, 1992, n/p.).

Observa-se que prevalece nesse ato internacional assegurar livremente o desenvolvimento econômico, social e cultural dos países-membros, e que para tanto deverão ser considerados e assegurados os Direitos Humanos, e os fundamentos educacionais, como instrumento de garantia e manutenção de direitos reconhecidos e vigentes em cada território.

Em 1969, em âmbito continental, foi celebrada a Convenção Interamericana de Direitos Humanos, popularmente conhecida como Pacto de San José da Costa Rica, entre 
os Estados-membros da Organização dos Estados Americanos (OEA), na cidade de São José, Costa Rica. Os signatários se comprometeram a respeitar os fundamentos proclamados na Declaração Universal dos Direitos Humanos, de 1948, dentre outros documentos, e adotar medidas legislativas ou de outra natureza que fossem necessárias para tornar efetivos os direitos humanos.

Reafirmando as intenções de defesa e promoção dos direitos humanos, em 1988 os membros da OEA acordaram um Protocolo Adicional à Convenção interamericana sobre Direitos Humanos, denominado "Protocolo de San Salvador", voltado, especialmente, para o tratamento dos direitos econômicos, sociais e culturais. No Brasil, o Decreto Federal $n^{\circ}$ 3.321, publicado no Diário Oficial da União em 31 de dezembro de 1999, promulga e internaliza no ordenamento pátrio o mencionado Protocolo.

O referido instrumento, em seu artigo 13, convenciona que a educação deverá orientar-se para o "pleno desenvolvimento da personalidade humana e do sentido de sua dignidade e deverá fortalecer o respeito pelos direitos humanos, pelo pluralismo ideológico, pelas liberdades fundamentais, pela justiça e pela paz" (BRASIL, 1999).

Desse modo, o Protocolo de San Salvador, como documento integrante, que reafirma e reconhece a DUDH e a própria Convenção Interamericana de Direitos Humanos, considera que assegurar a educação como um direito humano, passa pela garantia de um ensino primário, obrigatório e gratuito, do ensino secundário técnico e profissional e pela educação superior - nos dois últimos casos, pela introdução progressiva e gratuita.

Outro marco internacional, a II Conferência Mundial de Direitos Humanos de Viena, convencionada em 1993, pela ONU, em sua Declaração Final e Programa de Ação, e que referenda o Plano Mundial de Ação para a Educação em Direitos Humanos desse mesmo ano, reafirmou o respeito às liberdades individuais, à democracia, à tolerância e à paz. $O$ parágrafo 80 do Programa de Ações da mencionada Conferência estabelece que

A educação em direitos humanos deve incluir a paz, a democracia, o desenvolvimento e a justiça social, tal como previsto nos instrumentos internacionais e regionais de direitos humanos, para que seja possível conscientizar todas as pessoas em relação à necessidade de fortalecer a aplicação universal dos direitos humanos. (DECLARAÇÃO E PROGRAMA DE AÇÃO DE VIENA, 1993, n/p.).

Destaca-se a relevância deste documento ao tratar educação, especificamente, em direitos humanos, a partir de suas peculiaridades, visando a formação de consciência crítica 
para a promoção dos direitos universalmente reconhecidos e a participação popular e da sociedade civil como manifestação de uma cultura democrática.

Ao analisar os documentos influenciadores das propostas educacionais em direitos humanos na América Latina, Zenaide (2016) afirma que o Plano Mundial de Ação para a Educação em Direitos Humanos (1993) tem como ambiciosa meta: alcançar não só a educação formal e não-formal, mas também a processo de educação continuada dos profissionais da área. O plano propõe "incentivar os educadores a desenvolverem estratégias educativas democráticas que contribuam para promover uma cultura de paz baseada em direitos humanos". (ZENAIDE, 2016, p.51).

Desse modo, pertence ao plano de ação da Declaração e Programa de Ação de Viena (1993) que os governos dos países signatários criem métodos para apoiar o ensino nessa temática, com a inclusão nos currículos de todas as instituições de ensino, em caráter técnico e prático nas políticas educacionais em níveis nacional e internacional, tendo como máxima erradicar o analfabetismo.

O Programa de Ações que integra a referenciada Conferência Mundial de Direitos Humanos, no seu parágrafo 82 sugere a "proclamação de uma década das Nações Unidas para a educação em direitos humanos, visando a promover, estimular e orientar essas atividades educacionais" (DECLARAÇÃO E PROGRAMA DE AÇÃO DE VIENA, 1993), o que efetivamente consolidou-se com a edição pelo Alto Comissariado para os Direitos Humanos $(A C D H)$, da ONU, dos Planos de Ação Internacionais para a Educação em matéria de Direitos Humanos, devidamente regulamentada na Resolução $n^{\circ} 48 / 184$ de 1995. A relevância da referida Conferência para a solidificação do debate internacional sobre solidariedade, paz, tolerância e justiça social, por intermédio do acesso à educação, foi definido por Sacavino (2007, p. 461) da seguinte forma:

Não é possível construir um país socialmente justo se não for realizando, na prática, a afirmação da Conferência Mundial da ONU sobre Direitos Humanos, realizada em Viena em 1993, que afirma que a democracia, o desenvolvimento e o respeito pelos direitos humanos e liberdades fundamentais são conceitos interdependentes que se reforçam mutuamente, quando grandes contingentes de crianças, adolescentes e adultos estão, ainda, excluídos do direito à educação.

Em vista disso, a Declaração e Programa de Ações (1993), fundamentado nos reflexos históricos da falta de valorização e relevância da formação, do ensino e 
aprendizagem dos indivíduos, pelos Estados signatários, conduziu a própria sociedade à experiência do fracasso econômico, social e cultural. Em idêntico discurso aos demais atos internacionais em Direitos Humanos, defende a educação como meio eficaz de estabelecer relações sociais que promovam a paz e a tolerância. Para isto, faz-se necessário empreender esforços para o combate e/ou erradicação do analfabetismo, proporcionando aos cidadãos um senso crítico capaz de exigir melhores condições de vida em sociedade e a fortificação da personalidade humana.

A Década das Nações Unidas para a Educação em Direitos Humanos foi tratada na Resolução n 49/184 da ONU, aprovada pela Assembleia Geral em 23 de dezembro de 1994, e que compreenderia seus efeitos ao período de $1^{\circ}$ de janeiro de 1995 a 31 de dezembro de 2004. A estratégia da ONU era promover uma cultura universal em educação em direitos humanos, para a qual os sistemas de ensino dos países signatários deveriam inserir nos conteúdos curriculares e no desenvolvimento das práticas pedagógicas, temas sobre cidadania, tolerância, democracia, diversidade e identidade cultural, em todos os níveis de ensino. Além disso, a mencionada Década objetivava a formulação de técnicas e habilidades para a construção do conhecimento, pelo ensino formal e não formal, sobre os direitos humanos.

A Resolução n 49/184, da Assembleia Geral da ONU, é um marco fundamental para a educação em matéria de direitos humanos no território brasileiro, pois compreende a elaboração das diretrizes específicas dos planos, programas e a formação de comitês, em esferas nacionais, para a implementação e promoção da DUDH, de 1948, e do PIDESC, de 1966.

No Brasil, em 2003, no governo do Presidente da República, Luiz Inácio Lula da Silva, através da Lei Federal $n^{\circ}$ 10.683, foi criada a Secretaria Especial de Direitos Humanos (SEDH), com a finalidade de coordenar a política nacional de direitos humanos. Em conformidade com as diretrizes do Programa Nacional de Direitos Humanos (PNDH), objetivava-se articular iniciativas e apoiar projetos voltados para a proteção e promoção dos direitos humanos em âmbito nacional. (BRASIL, 2003).

A SEDH, em atendimento às indicações da Resolução n 49/184 da Assembleia Geral da ONU, criou o Comitê Nacional de Educação em Direitos Humanos, através da 
Portaria $n^{\circ}$ 98/2003 ${ }^{1}$ da SEDH/PR, com o objetivo de elaborar e aprovar o Plano Nacional de Educação em Direitos Humanos (PNEDH), além de estimular, nas esferas estaduais e municipais, a criação de instâncias para a formulação de políticas públicas de educação em direitos humanos. Em observância ao período estipulado como Década das Nações Unidas para a Educação em Direitos Humanos (1995/2004), o Plano, portanto, foi lançado em sua primeira versão em dezembro de 2003, e sujeito a releituras e revisões até chegar à edição da última versão em 2006.

\section{Aos planos - as expectativas e as bases legais da educação em direitos humanos no Brasil}

Na América Latina, de modo geral, a questão dos direitos humanos ganhou vulto e centralidade na segunda metade do século XX, com o advento das ditaduras civil-militares. No Brasil, entre os anos de 1964 e 1985, a luta contra o arbítrio e contra todo tipo de violência causada pelo autoritarismo e violência do Estado, fortificou os movimentos sociais e as organizações da sociedade civil, em prol da defesa dos direitos civis, políticos e das liberdades individuais. Com o fim da ditadura civil-militar no Brasil, a preocupação com a garantia e efetividade com os direitos econômicos, sociais e culturais, prerrogativas constantemente negadas em países marcados pelas desigualdades sociais de toda sorte, passaram a integrar as agendas políticas dos governos.

A democracia brasileira pode ser considerada jovem, haja vista os curtos e segmentados períodos democráticos que o país vivenciou após a Proclamação da República. Nesse sentido, nossa incipiente experiência democrática revela um processo inicial de conscientização e de luta pelos direitos humanos. Nas palavras de Bonavides (1998, p.17), “a democracia, por conseguinte, não é apenas forma de governo senão

\footnotetext{
${ }^{1}$ A Portaria $n^{\circ} 83$ de 21 de fevereiro de 2008, que revogou a Portaria $n^{\circ} 98$ de 2003, ambas da SEDH, visou a reestruturação na composição dos membros do Comitê Nacional de Educação em Direitos Humanos, e tem como pressuposto: “Art. $1^{\circ}$ Instituir o Comitê Nacional de Educação em Direitos Humanos, colegiado de caráter consultivo vinculado à Secretaria Especial dos Direitos Humanos, com as seguintes finalidades: I - Propor, monitorar e avaliar a Política Nacional de Educação em Direitos Humanos; II - Propor, monitorar e avaliar a implementação do Plano Nacional de Educação em Direitos Humanos; III - Assessorar e emitir parecer quando consultado a Secretaria Especial dos Direitos Humanos da Presidência da República em questões de educação em direitos humanos; IV - Colaborar na articulação com órgãos públicos e privados, movimentos sociais e outros, nacionais e internacionais, para a implementação da Política Nacional de Educação em Direitos Humanos; V - Sugerir a proposição de projetos de lei sobre educação em direitos humanos; VI Estimular a criação de instâncias para a formulação, implementação e avaliação de políticas de educação em direitos humanos nas esferas federal, estadual e municipal; e VII - Propor a elaboração de estudos, pesquisas e material didáticopedagógico sobre educação em direitos humanos" (BRASIL, 2008).
} 
princípio constitucional da mais subida juridicidade na hierarquia dos ordenamentos", sob o qual os direitos humanos estão necessariamente associados.

O último quartel do século XX e as primeiras décadas do século XXI tornaram-se um período de tomada de consciência político-social de que a violação de direitos humanos no Brasil é uma trágica realidade cotidiana, atingindo, prioritariamente, os grupos sociais subalternizados e historicamente vitimizados, como o de mulheres, homossexuais, negros, imigrantes, pessoas com deficiências, entre outros. Podemos perceber que, justamente, os grupos mais sacrificados no gozo de direitos sofrem de enorme carência de conhecimentos e informações sobre as maneiras de reivindicá-los.

Desse cenário, surge com muita força social a positivação de direitos e garantias, embora seja forçoso reconhecer não ser suficiente a previsão apenas no plano político e jurídico. Bonavides defende que com a positivação dos direitos humanos há uma transição do estágio de "programáticos, para o espaço normativo dos sistemas constitucionais. Mas nem por isso perdem o caráter de sua universalidade tutelar ao se tornam doravante direitos fundamentais" (BONAVIDES, 1998, p. 17).

É preciso, acima de qualquer coisa, um trabalho de formação, de educação, no sentido mais amplo, que parta da consciência dos valores democráticos para o convencimento de que a transformação dos direitos humanos em práticas sociais é o único caminho para a construção de uma sociedade mais justa.

A origem do movimento por uma educação em direitos humanos no Brasil deu-se com o debate internacional promovido pela Organização das Nações Unidas para a Educação, a Ciência e a Cultura (UNESCO), no final da década de 1990 e início dos anos 2000. Em vista de uma resposta ao movimento mundial, o Governo Federal iniciou um processo de debate e criação de um Plano Nacional de Educação em Direitos Humanos (PNEDH). Esse documento é fruto do compromisso do Estado com a busca pela afirmação e concretização dos direitos humanos no Brasil. O PNEDH incorpora aspectos dos principais documentos internacionais de direitos humanos, dos quais o país é signatário, agregando demandas sociais pela efetivação da democracia, do desenvolvimento e da justiça social.

O debate educacional que fundamenta a educação em direitos humanos sofreu mudanças ao longo dos anos. Segundo Candau (2007), de 1980 aos anos de 2000, as questões de fundo se reorientaram de um aspecto mais estrutural, político-social, para um aspecto multiculturalista, de defesa das minorias. Nas palavras da autora, a escamoteação 
do debate teórico-social se expressa “[...] na transição modernidade/pós-modernidade, no contexto de democracias débeis ou de 'baixa intensidade' e de hegemonia neoliberal” (CANDAU, 2007, p. 403).

A temática da educação para direitos humanos na década de 1980, nos países que passaram por um processo de transição democrática depois de experiências de ditaduras, como é o caso brasileiro, foi introduzida como um componente político-educacional orientado para o fortalecimento do regime democrático. Já nos primeiros anos de 2000, a realidade é outra, e o clima político-social, cultural e ideológico se configura de modo diferente. O país vivenciou um contexto de políticas neoliberais, de debilitação da sociedade civil, de crescente exclusão social e falta de horizonte utópico (CANDAU, 2007). Nesse sentido, a imagem de um projeto societário democrático que se assumiu nos anos de 1970 e 1980 está questionada. As mudanças ocorridas no mundo, de ordem política, teórica, ideológica e pedagógica, exigiram revisão no projeto histórico de educação em direitos humanos.

Nessa perspectiva, como fruto da nomeada "transição modernidade/pósmodernidade" (CANDAU, 2007, p. 403), a polissemia do conceito de direitos humanos, permitiu, por vezes, a sua substituição por definições que restringem a educação em direitos humanos a uma educação de valores, inibindo seu caráter político.

O debate ético-jurídico dos Direitos Humanos, no entanto, surge como uma conquista histórica pelo reconhecimento de que todo homem tem direito de ser, em todos os lugares, reconhecido como pessoa (DECLARAÇÃO, 1948) é, de certo modo, uma proteção jurídica dada por constituições proclamadas em contextos democráticos. Nesta proposta, a Constituição Federal de 1988 (CF/1988), dogmática, rígida e compromissória, fruto de uma proposta de estado pluralista e democrático, tem como princípio fundamental reger suas relações internacionais com prevalência dos Direitos Humanos (Título I, artigo $4^{\circ}$, inciso II). Os Tratados Internacionais, aprovados dentro do rigor técnico e legal exigido para as Emendas Constitucionais, adquirem natureza de norma constitucional.

Os Direitos Fundamentais contidos na CF/1988 (Título II, do artigo $5^{\circ}$ ao 17) são valores contemplados por uma sociedade cujo retrocesso, ou eliminação, é vedada pela natureza de conquista da humanidade e se fundamentam nos diversos pactos internacionais dos quais Brasil é signatário em matéria de Direitos Humanos. Dentre esses 
pactos, citamos aqueles que já apresentamos anteriormente, as proposições da Declaração Universal dos Direitos Humanos promulgada pelas Nações Unidas (ONU), de 1948, e do Pacto Internacional dos Direitos Econômicos, Sociais e Culturais (PIDESC), de 1966.

No âmbito interno, diversas legislações foram promulgadas com a proposta de regulamentar matérias com fundamentos em direitos humanos, tais como: o Estatuto da Criança e do Adolescente (Lei Federal $n^{\circ}$ 8.069/1990); Lei que define os crimes resultantes de preconceito de raça ou de cor (Lei Federal $n^{\circ}$ Lei 7.716/89); Lei que reconhece como mortas pessoas desaparecidas em razão de participação, ou acusação de participação, em atividades políticas, no período de 2 de setembro de 1961 a 15 de agosto de 1979 (Lei Federal $n^{\circ}$ 9.140/95); Lei que define o Crime de Tortura (Lei Federal $n^{\circ}$ 9.455/97), entre outras.

Especificamente no campo da educação, há diversas legislações que se dedicaram a estabelecer critérios, diretrizes e métodos com ênfase na valorização e promoção da Educação em Direitos Humanos, são elas: a Lei de Diretrizes e Bases da Educação Nacional (Lei Federal n 9.394/1996); Parâmetros Curriculares Nacionais (PCN), de 1997; Programa Nacional de Extensão Universitária (Proext); Diretrizes Nacionais Curriculares para a Educação Básica; Lei que inclui no currículo oficial da Rede de Ensino a obrigatoriedade da temática História e Cultura Afro-Brasileira (Lei Federal n 10.639/2003); Plano Nacional de Educação (Lei Federal n 13.005/2014); Base Nacional Comum Curricular de 2017, e correlatas.

O cenário político-jurídico, atualmente, ainda é pela consolidação da redemocratização iniciada em meados da década de 1980, e visa romper com uma herança histórica de desigualdades e injustiças sociais. Nesse movimento, a CF/1988 que notabilizou o Estado Democrático de Direito, também elegeu, como um dos pilares da República, a cidadania, que por sua vez, está embasada nos princípios da liberdade, igualdade, equidade, diversidade, o que afirma sua universalidade e interdependência (BRASIL, 2006), e fortalece a proposta da Educação em Direitos Humanos, para o desenvolvimento de capacidades e senso crítico dos educandos. A Lei de Diretrizes e Bases da Educação Nacional de 1996 segue a mesma linha, assim como na Carta Magna, tem-se como fundamento o pleno exercício da cidadania, assegurando ao aluno a formação comum indispensável para o exercício desta. 
Como se notabilizou a necessidade de uma educação em direitos humanos como meio para atingir finalidade educacional de formar para a cidadania e contribuir com a consolidação da democracia no país, as ações educacionais (escolares e não-escolares) passaram a ser alvo de reflexões e propostas. Podemos citar como iniciativas para realização dessa feita o Plano Nacional de Educação em Direitos Humanos (PNEDH) e seus correlato curricular, as Diretrizes Nacionais Curriculares em Direitos Humanos (DNEDH).

Em 1996 foi iniciado a elaboração do Programa Nacional de Direitos Humanos (PNDH), o qual, atendendo ao compromisso firmado pelo Brasil em 1994, pela implementação da Década da Educação em Direitos Humanos da ONU. Dentre os compromissos internacionais assumidos estava inclusa a edição do Plano Nacional de Educação em Direitos Humanos (PNEDH), cujo conteúdo indica as proposições para a implantação nas redes de ensino da EDH, tomando como base os principais tratados internacionais em direitos humanos, dos quais o Brasil é signatário.

A primeira versão do PNEDH foi publicada em 2003, logo após a criação da Secretaria de Direitos Humanos da Presidência da República. Nos anos de 2004 e 2005, a sociedade civil, instituições públicas e privadas de ensino e organismos internacionais desenvolveram estudos para aperfeiçoar o PNEDH, o que culminou em 2006 na segunda versão, cujo documento é a atual fonte diretiva para o debate no país da cultura em e para a educação em direitos humanos.

Estruturado em 05 grandes eixos, quais sejam: a Educação Básica, Ensino Superior, Educação Não-Formal, Educação dos Profissionais dos Sistemas de Justiça e Segurança Pública e Educação e Mídia. Destaca-se como objetivo do plano a transversalidade da EDH nas políticas públicas. De acordo com Sacavino (2007), o PNEDH (2006), enquanto política pública, entende os Direitos Humanos

no seu sentido amplo, decorrentes da dignidade do ser humano, abrangendo, entre outros: os direitos à vida com qualidade, à saúde, à educação, à moradia, ao lazer, ao meio ambiente saudável, ao saneamento básico, à segurança, ao trabalho e à diversidade cultural. (SACAVINO, 2007, p. 462).

A EDH como entendida no Plano é uma proposta de afirmação de valores, de formação de consciência cidadã, de fortalecimento da democracia, além de reparação das diversas formas de violência, e desse modo, o meio indispensável para corroborar com a 
garantia e acesso a outros direitos fundamentais. Além do fortalecimento das práticas democráticas no território nacional, por intermédio da educação, o PNEDH pretende a interdisciplinaridade e à transdisciplinaridade do tema, como ferramenta de alcance e de propagação do conhecimento (BRASIL, 2006).

Percebe-se que o Plano se preocupou em difundir uma cultura em matéria de direitos humanos por intermédio da educação, tanto na formação dos profissionais da educação, quanto naqueles inseridos no cenário da segurança pública e justiça. Com isso, a proposta assume uma dimensão que extrapola a educação formal em espaços próprios para o ensino, e alcança grupos comunitários de bairros, associações, sindicatos, ambientes de trabalho, até a práticas cotidianas em âmbito familiar, interligando todas as práticas ao eixo da Educação e Mídia. Nesse caso, os meios de comunicação são utilizados como ferramenta dinâmica e célere de multiplicação do conhecimento.

Em termos curriculares, como instrumentalização das propostas do PNEDH, os direitos humanos foram contemplados na legislação educacional pela LDB/1996, possui diretrizes curriculares nacionais próprias e aparece na Base Nacional Comum Curricular (BNCC), ainda que de modo difuso. Para a Educação Básica, a LDB/1996 determina que os currículos devem ter uma base nacional comum, acrescida de uma parte diversificada que atenda os anseios e peculiaridades regionais de cada escola, considerando, ainda, que o estudo dos direitos humanos será apresentado nesses currículos como tema transversal (BRASIL, 1996). A transversalidade do debate sobre Direitos Humanos nos currículos da educação básica fundamenta-se por sua natureza abrangente e plural, sem, necessariamente, serem criadas áreas ou disciplinas para a inserção do conteúdo em sala de aula. As Diretrizes Nacionais para a Educação em Direitos Humanos (DNEDH) ao abordar as práticas pedagógicas para infundir o tema nos currículos da Educação Básica, também o caracteriza no aspecto transversal, como sendo aqueles que "devem ser trabalhados a partir do diálogo interdisciplinar" (BRASIL, 2012).

A Resolução $n^{\circ} 1$ do $C N E / C P$, que estabelece as Diretrizes para uma EDH a serem observadas pelos sistemas de ensino e suas instituições, dispõe em seu artigo $6^{\circ}$ que a EDH, de modo transversal, deverá ser considerada na construção dos

Projetos Político-Pedagógicos (PPP); dos Regimentos Escolares; dos Planos de Desenvolvimento Institucionais (PDI); dos Programas Pedagógicos de Curso (PPC) das Instituições de Educação Superior; dos materiais didáticos e pedagógicos; do modelo de ensino, pesquisa e 
extensão; de gestão, bem como dos diferentes processos de avaliação. (BRASIL, 2012).

Após um longo período de debates e estudos entre diferentes grupos do sistema de ensino e da sociedade brasileira, a BNCC foi referendada na Resolução $n^{\circ} 2$ do CNE/CP e publicada em 22 de dezembro de 2017. Quanto à natureza jurídica, a BNCC pode ser considerada como instrumento normativo oriundo do poder executivo federal, o qual compete fixar conteúdos curriculares mínimos para a Educação Básica, e que deverão ser observados, obrigatoriamente, pelos sistemas de ensino nacional.

A Base é estruturada a partir do conceito desenvolvimento de competência, que englobam os conhecimentos, habilidades, atitudes e valores para a formação do educando, de modo que as decisões pedagógicas devem ser orientadas pelo mesmo. Reproduzindo a proposta pedagógica marcada na LBD (1996) e nas DNEDH (2013), a BNCC traz a Educação em Direitos Humanos, também, como tema transversal nas disciplinas da Educação Básica. A temática dos direitos humanos foi inserida, de forma direta e indireta, nas competências gerais para a Base Nacional Comum Curricular; nas competências específicas de linguagem para o ensino fundamental; nas habilidades em língua portuguesa do $8^{\circ}$ e do $9^{\circ}$ ano; nas competências específicas de ciências humanas para o ensino fundamental; nas habilidades de história do $5^{\circ}$ ano; nas habilidades de história do $9^{\circ}$ ano; nas competências específicas de ensino religioso para o ensino fundamental; e, nas habilidades do ensino religioso do $7^{\circ}$ ano.

Com propostas diferentes para as competências gerais e específicas, e para as habilidades, a Base preocupou-se em promover e promulgar os direitos humanos, enquanto políticas afirmativas, tanto no aspecto da defesa quanto do conhecimento, ao propiciar a formação integral dos indivíduos e da personalidade humana e combater qualquer forma de violência social.

Como visto, a EDH no Brasil se objetiva em planos que seguem orientações expressas em acordo, protocolos e pactos internacionais de promoção dos direitos humanos e da dignidade humana. Há de se considerar os esforços da sociedade civil organizada em defender a garantia legal da formação de uma cultura em direitos humanos nas instituições educacionais brasileiras. Contudo, devemos não esquecer que essas proposições, em geral, são letras mortas, como tantos outros temáticas relevantes e negligenciadas nos currículos escolares. 
Nos dias atuais, a educação em direitos humanos admite leituras que alargam seu sentido, que passaram a englobar a educação para o trânsito, direitos do consumidor, questões de gênero, étnicas e de meio ambiente. Em tese, tais temas eminentemente multiculturais podem ser esvaziados do seu conteúdo político, enfatizando questões culturalistas. Não se trata aqui de fazer juízos de valor quanto à natureza e à importância dos temas, senão o de alertar o risco que se corre ao ramificar o debate sobre direitos humanos em inúmeras dimensões, em detrimento de uma visão mais articulada e confluente entre os diversos temas, tendo como seus principais fundamentos a democracia, a igualdade, as liberdades e a cidadania.

Nesse ponto, notamos que o "horizonte de expectativas" (KOSELLECK, 2006) apresentado pelo ordenamento jurídico nacional e internacional desde segunda metade do século $X X$, até as duas primeiras décadas do século $X X I$, foi de uma efetiva implementação e instrumentalização da EDH no contexto educacional, por intermédio de práticas educativas e da propagação de uma cultura em direitos, na dimensão do aprendizado acerca dos direitos e deveres, e de garantias e proibições de condutas em prol da preservação da vida, da cidadania, da democracia e das diversidades. Nos "espaços de expediência" (KOSELLECK, 2006), por outra via, como acima disposto, a ênfase nos Planos e Programas nacionais está presente nesta última categoria, qual seja: o debate acerca das diversidades. Muitas das vezes, no entanto, desfocado e diluído em inúmeras vertentes, que almejam, dar vozes e fortalecer grupos sociais historicamente excluídos. A crítica acerca deste último ponto reside no enfraquecimento da proposta educativa em DH contida em todo o arcabouço mundial, uma vez que, as discussões isoladas sobre direitos humanos, equivocadamente, ganham aparência de uma efetiva cultura em DH.

Há de se reconhecer, no entanto, que as garantias previstas na legislação educacional brasileira devem ser celebradas, sem perder de vista que a sua objetivação em propostas educacionais ainda estão para ser construídas e implementadas. Urge a necessidade de uma formação humana calcada nos valores fundamentais dos direitos humanos, bem como, a construção de uma sociedade efetivamente democrática. Acreditamos que a educação escolar é importante e potente ferramenta para esse objetivo, mas não a única. Por isso, esforços devem ser empreendidos para a mobilização e efetivação de práticas educacionais e pedagógicas capazes de contribuir com uma 
formação humana calcada na dignidade humana e com a constituição de uma sociedade mais justa e igualitária.

\section{CONSIDERAÇÕES FINAIS}

Desse modo, com base no panorama por nós exposto sobre a historicidade da Educação em Direitos Humanos no Brasil e, para tanto, percorrendo os principais documentos internacionais sobre Direitos Humanos, é possível perceber que o direito fundamental à educação sempre teve centralidade para o alcance e efetivação das condições dignas de vida em sociedade.

A recorrência do debate envolto pelos Direitos Humanos em âmbito global já era um anseio da Declaração Universal dos Direitos do Homem de 1948, e para a educação nessa temática foram criados mecanismos e técnicas de adoção no campo legislativo, com padrões mínimos, nos países considerados democráticos.

Para isso, documentos, como o Protocolo de São Salvador, defendem o acesso à educação como ferramenta do fortalecimento das liberdades. Enquanto a II Conferência Mundial de Direitos Humanos de Viena de 1993 recomenda aos governos dos países signatários o desenvolvimento de métodos para apoiar o ensino em direitos humanos, bem como sua inclusão nos currículos de todas as instituições de ensino, com a finalidade de erradicar o analfabetismo.

O estudo detido da legislação indicada neste estudo, demonstra que a defesa dos direitos humanos assume uma natureza nominal, em detrimento do discurso de liberdade, democracia e paz, e em benefício das categorias, historicamente vulneráveis, como por exemplo, das mulheres, negros, indígenas, quilombolas, grupos étnicos, lésbicas, gays, bissexuais, transexuais, travestis, transgêneros, intersexuais e simpatizantes, entre outros. Isso reorganizou o cenário do estudo sobre direitos humanos, que passou a incluir o debate sobre discriminação e violência de cunho sexual, religioso, cultural. A estrutura fundante, porém, para toda e qualquer prática pedagógica em direitos humanos será a afirmação de direitos fundamentais, a vedação ao retrocesso, a defesa da dignidade humana e a cultura da paz, ainda que diante das constantes transformações e atualizações do debate para atender os anseios da sociedade contemporânea.

Como afirma Vera Maria Candau et alii (2000, p. 13), "a luta pelos direitos humanos passa por questões concretas como a raça, a classe social, o gênero, a religião, a cultura". 
Alguns sujeitos sociais são protagonistas diretos dessas lutas, já que sentem as consequências diretas dos desrespeitos aos seus direitos. Já a outros, cabe posição de solidariedade na luta, postura de quem apoia, em última instância, os esforços para que os direitos humanos sejam direitos efetivos para todos.

Em sociedades, como a brasileira, portanto, marcada pela desigualdade social, exclusão, pelos conflitos, a abordagem dos direitos humanos na seara normativa se torna imperiosa, central e uma relevante conquista. A despeito disto, para o campo educacional, a efetivação dos direitos humanos e sua inserção da rede de ensino depende do efetivo envolvimento dos poderes executivo e legislativo e da sociedade civil. O poder de fiscalização do Estado e da sociedade, atrelados ao dever estatal de cumprir as políticas públicas educacionais e de fomentar as práticas educacionais projetadas nestes documentos normativos, são medidas que possibilitarão a efetiva promoção à cultura em direitos humanos projetada em âmbito internacional.

Diante desse contexto, a afirmação de uma cultura dos direitos humanos que penetre todas as práticas sociais, e seja capaz de favorecer o processo de democratização, bem como de articular a afirmação dos direitos fundamentais de cada pessoa ou grupos sociais/étnicos transcende a norma positivada, ao passo que dela depende. Ou seja, o complexo normativo posto vigente sobre os direitos humanos, clama políticas públicas de divulgação, de fomento e educacionais, capazes de serem sentidas e vivenciadas pela coletividade.

\section{REFERÊNCIAS}

ABBAGNANO, Nicola. Dicionário de filosofia. $5^{\circ}$ ed. São Paulo: Martins Fontes, 2007.

BARBOSA, Rui. Oração aos moços. $5^{\circ}$ edição. Rio de Janeiro: Casa de Rui Barbosa, 1999.

BONAVIDES, Paulo. Os direitos humanos e a democracia. In. SILVA, Reinaldo Pereira e. (ORG.). Direitos humanos como educação para a justiça. São Paulo: LTr, 1998.

BRASIL. Base Nacional Comum Curricular: versão encaminhada ao Conselho Nacional de Educação. Ministério da Educação, Brasília, 2017.

BRASIL. Constituição Política do Império do Brazil. Rio de Janeiro, 1824. Disponível em http://www.planalto.gov.br/ccivil_03/Constituicao/Constitui\%C3\%A7a024.htm. Acesso em 03/09/2018. 
BRASIL. Constituição da República Federativa do Brasil. Brasília, DF: Senado Federal: Centro Gráfico, 1988.

BRASIL. Decreto ${ }^{\circ} 591$ de 06 de julho de 1992. Ato Internacional. Pacto Internacional sobre Direitos Econômicos, Sociais e Culturais. Diário Oficial, Brasília, DF, 07 de jul. de 1992.

BRASIL. Decreto n 3.321 de 31 de Dezembro de 1999. Protocolo Adicional à Convenção Americana sobre Direitos Humanos em Matéria de Direitos Econômicos, Sociais e Culturais "Protocolo de São Salvador". Diário Oficial, Brasília, DF, 31 de dez. de 1999.

BRASIL. Lei Federal n 9.394 de 20 de dezembro de 1996. Estabelece as diretrizes e bases da educação nacional. Diário Oficial, Brasília, DF, 23 de dez. de 1996.

BRASIL. Lei Federal $n^{\circ} 10.683$ de 28 de maio de 2003. Estabelece a organização da Presidência da República e dos Ministérios. Diário Oficial, Brasília, DF, 29 de maio de 2003.

BRASIL. Lei Federal $n^{\circ} 13.005$ de 25 de Junho de 2014. Estabelece o Plano Nacional de Educação. Diário Oficial, Brasília, DF, 26 de jun. de 2014.

BRASIL. Parâmetros curriculares nacionais: apresentação dos temas transversais, ética. Secretaria de Educação Fundamental, Brasília, 1997.

BRASIL, Comitê Nacional de Educação em Direitos Humanos; Secretaria Especial de Direitos Humanos, Ministério da Educação, Ministério da Justiça, UNESCO. Plano Nacional de Educação em Direitos Humanos. Brasília, 2003.

BRASIL, Comitê Nacional de Educação em Direitos Humanos; Secretaria de Direitos Humanos, Ministério da Educação, Ministério da Justiça e UNESCO. Plano Nacional de Educação em Direitos Humanos. Brasília, 2006.

BRASIL, Ministério da Educação/Conselho Nacional de Educação. Diretrizes Nacionais para a Educação em Direitos Humanos. Brasília: MEC/CNE, 2013.

BRASIL. Parecer $\mathbf{n}^{\circ} 8$ de março de 2012. Projeto de resolução que estabelece as Diretrizes Nacionais para a Educação em Direitos Humanos. Conselho Nacional de Educação/Conselho Pleno, Brasília, 2012.

BRASIL. Portaria $\mathbf{n}^{\circ} 83$ de fevereiro de 2008. Secretaria Especial de Direitos Humanos, Brasília: Diário Oficial da União (DOU). Publicado no DOU, Seção 1, n 36, de 22 de fevereiro de 2008.

BRASIL. Resolução $\mathbf{n}^{\circ} \mathbf{1}$ de maio de 2012. Estabelece Diretrizes Nacionais para a Educação em Direitos Humanos. Conselho Nacional de Educação/Conselho Pleno, Brasília, 2012.

BRASIL. Resolução $\mathbf{n}^{\circ} 2$ de dezembro de 2017. Estabelece a Base Nacional Comum Curricular. Conselho Nacional de Educação/Conselho Pleno, Brasília, 2017. 
BRASIL, Secretaria Especial dos Direitos Humanos da Presidência da República. Programa Nacional de Direitos Humanos (PNDH). Brasília: SDH/PR, 1996.

CANDAU, Vera Maria. Educação em direitos humanos: desafios atuais. In. SILVEIRA, Rosa Maria Godoy et al. (Orgs.). Educação em Direitos Humanos: fundamentos teóricometodológicos. João Pessoa: Editora Universitária, 2007.

CANDAU, Vera Maria et al. Tecendo a cidadania: oficinas pedagógicas de direitos humanos.

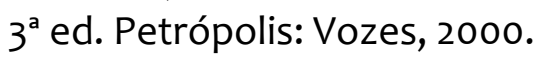

DECLARAÇÃO E PROGRAMA DE AÇÃO DE VIENA, de 1993. Disponível em http://www.dhnet.org.br/direitos/anthist/viena/declaracao_viena.htm. Acesso em 24/01/18.

DECLARAÇÃO UNIVERSAL DOS DIREITOS HUMANOS, de 10 de Dezembro de 1948. UNIC / Rio / 005 - Agosto 2009. Disponível em http://www.onu.org.br/img/2014/og/DUDH.pdf. Acesso em 24/01/18.

KOZELLECK, Reinhardt. Futuro Passado: Contribuições à Semântica dos tempos históricos. Rio de Janeiro: Contraponto: Ed. PUC-Rio, 2006.

MONDAINI, Marco. Direitos Humanos no Brasil. 2. ed. São Paulo: Contexto, $2013 a$.

SACAVINO, Susana. Direito humano à educação no Brasil: uma conquista para todos/as? In. SILVEIRA, Rosa Maria Godoy et al. (orgs.). Educação em Direitos Humanos: fundamentos teórico-metodológicos. João Pessoa: Editora Universitária, 2007.

SILVEIRA, Rosa Maria Godoy et al. (orgs.). Educação em Direitos Humanos: fundamentos teórico-metodológicos. João Pessoa: Editora Universitária, 2007.

ZENAIDE, Maria de Nazaré Tavares. Introdução. In. SILVEIRA, Rosa Maria Godoy et al. (orgs.). Educação em Direitos Humanos: fundamentos teórico-metodológicos. João Pessoa: Editora Universitária, 2007. 